\title{
New Chiral Catalyst, $t$-Butyllithium Complexed with Axially Chiral Diamine, for Asymmetric Polymerizations of Triphenylmethyl Methacrylate and Its 2-Pyridyl Derivative
}

\author{
Shigeyoshi KANOH, Takeshi SUMINO, Naotaka KAWAGUCHI, \\ Masatoshi MOTOI, and Hiroshi SUDA* \\ Department of Chemistry and Chemical Engineering, Faculty of Engineering, \\ Kanazawa University, 2-40-20 Kodatsuno, Kanazawa 920, Japan
}

(Received December 23, 1987)

\begin{abstract}
Asymmetric polymerizations of achiral methacrylates such as bulky triphenylmethyl and diphenyl-2-pyridylmethyl esters were investigated in toluene at $-78^{\circ} \mathrm{C}$. $t$-Butyllithium complexed with a tetramethylethylenediamine derivative having an axially chiral 6,6'dimethylbiphenyl-2,2'-diyl substituent (1) at $-78^{\circ} \mathrm{C}$ was found to be a versatile chiral initiator for the above polymerizations. The produced poly(ester)s were easily soluble in THF, because of the limited molecular weights. The polymers of helical conformation showed large optical rotations, whose signs depended on the chirality of the used 1.

KEY WORDS Asymmetric Polymerization / Helix / Triphenylmethyl Methacrylate / Diphenyl-2-pyridylmethyl Methacrylate / Axially Chiral Biphenyl / Tetramethylethylenediamine Derivatives / Butyllithium /
\end{abstract}

In past years, much attention has been focused on optically active polymers obtained from bulky methacrylates such as triphenylmethyl methacrylate (TrMA $)^{1-3}$ and diphenyl-2-pyridylmethyl ester (D2PyMA). ${ }^{4.5}$ The optical activity of these polymers is attributed to the helical conformation stabilized by the isotactic sequence of bulky ester groups. ${ }^{6}$ The conformation prevailing in one screw sense is formed through asymmetric polymerizations with chiral anionic initiators. ${ }^{1-5}$ The molecular weights of the polymers are critical for their solubility. Especially organic solventsoluble parts have been found by Okamoto et al. to be useful materials as chiral solid phases of high performance liquid chromatography for the optical resolution of various racemic substances. ${ }^{5,7}$

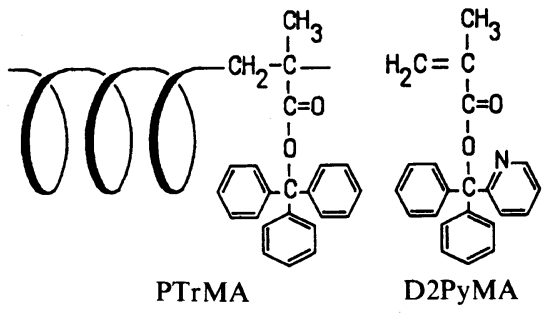

We have already reported that chiral complexes of organolithiums with tetramethylethylenediamine (TMEDA) derivatives (1 and 2) having biaryl substituents also serve as excellent catalysts for the asymmetric polymerization of TrMA. ${ }^{8,9}$ It is considered that the high stereoselectivities of these catalysts are ascribed to complementary effects between the chirality-recognizing ability of biaryl units and the flexibility of the TMEDA side-arm for

\footnotetext{
* Author to whom all correspondence should be addressed.
} 
chelation to lithium ions. ${ }^{8}$ The helical senses of the produced polymers depend only upon the atropisomeric chirality of the biaryl modifiers of the ligands employed. ${ }^{9}$

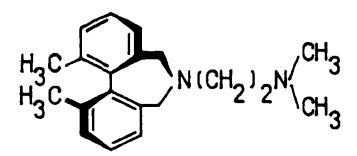

(R)-1

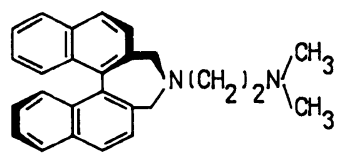

(R)-2

\section{EXPERIMENTAL}

\section{Materials}

Purifications of TrMA and toluene were previously reported. ${ }^{8}$ The preparation and purification of D2PyMA were carried out according to the reported method. ${ }^{5} \mathrm{Mp} 129.5-$ $130.5^{\circ} \mathrm{C}$ ). (lit. ${ }^{5} \mathrm{mp} 129-130^{\circ} \mathrm{C}$ ). $n$-BuLi was prepared from butyl chloride and lithium metal in hexane under argon, and the solvent was replaced with purified toluene on a vacuum line. Commercial $t$-BuLi (Kanto Chemical Co.) was used as a pentane solution. The concentrations of the alkyllithiums were adjusted to $c a$. $1.0 \mathrm{moll}^{-1}$, and determined before use.

The chiral ligand 1 was prepared from optically pure $6,6^{\prime}$-dimethylbiphenyl-2,2'-dicarboxylic acid $^{10)}$ according to the previously reported method. ${ }^{8)}(R)-1:[\alpha]_{\mathrm{D}}^{25}+43.0^{\circ}(c=$ $\left.1.0 \mathrm{~g} \mathrm{dl}^{-1}, \mathrm{THF}\right) ;(S)-1:[\alpha]_{\mathrm{D}}^{25}-42.9^{\circ}$.

\section{Polymerization Procedure}

The polymerization was carried out in an $\mathrm{H}$ branched glass ampoule under a dry nitrogen atmosphere. A solid monomer $(1.0 \mathrm{~g})$ was placed in one side-tube of the ampoule, and dried by evacuation. The monomer was dissolved in $15 \mathrm{ml}$ of dry toluene, and the ampoule was cooled to a given temperature at which the catalyst was prepared. A toluene solution $(5 \mathrm{ml})$ of optically active 1 was mixed with an equimolar amount of $t$-BuLi in the other sidetube. The whole ampoule was then immersed in a dry ice/methanol bath, and sealed with stoppers under nitrogen. After being cooled, the two solutions were well mixed by turing the ampoule upside down as quickly as possible. The polymerization thus initiated was done at $-78^{\circ} \mathrm{C}$ and then terminated by the addition of a small amount of methanol. The polymer that precipitated from $200 \mathrm{ml}$ of methanol was worked up as described previously. ${ }^{8,9}$

\section{Measurements}

Optical rotations were measured on a JASCO DIP-360 polarimeter at $25^{\circ} \mathrm{C}$. Gel permeation chromatograms (GPC) were run on HITACHI GPC columns (GELPACK GLA100M and GL-A140 in series) with a JASCO 880-PU pump. THF was used as an eluent $\left(1.0 \mathrm{ml} \mathrm{min}{ }^{-1}\right)$. Elutions were monitored on a JASCO RID-300 RI detector or together with the above polarimeter using a $5-\mathrm{cm}$ flow cell $(0.35 \mathrm{ml})$ with no-filtered mercury light. ${ }^{1} \mathrm{H}$ and ${ }^{13} \mathrm{C}$ NMR spectra were taken on a JEOL JNM-FX-100S spectrometer at 100 and $25 \mathrm{MHz}$, respectively, using internal $\mathrm{Me}_{4} \mathrm{Si}$. Gas chromatographic mass (GC-mass) spectra were obtained on a HITACHI M-80 mass spectrometer.

\section{RESULTS AND DISCUSSION}

\section{Polymerization of $\operatorname{Tr} M A$}

As reported previously, ${ }^{9} n$-BuLi was highly activated by complexation with ligands of the TMEDA-type such as $\mathbf{1}$ and $\mathbf{2}$, and consequently the $n$-BuLi complexes lithiated toluene smoothly at room temperature. The resulting benzyllithium (BzLi) complexes were found to be excellent catalysts for the polymerization of TrMA. ${ }^{9}$ In addition, we examined the asymmetric carbonyl addition of organolithium compounds to aldehydes with the chiral assistance of $1 .^{11}$ In the course of the study, it was noticed that $n$-BuLi complexed with 1 in toluene at $-40^{\circ} \mathrm{C}$ reacted with benzaldehyde to give optically active 1-phenyl-1-pentanol in a high yield, while a related complex prepared at room temperature afforded a benzylated 
Table I. Asymmetric polymerization of TrMA using chiral complexes of alkyllithiums with 1 in toluene for $24 \mathrm{~h}$ at $-78^{\circ} \mathrm{C}^{\mathrm{a}}$

\begin{tabular}{|c|c|c|c|c|c|c|c|c|c|}
\hline \multirow{3}{*}{$\begin{array}{l}\text { Run } \\
\text { no. }\end{array}$} & \multicolumn{3}{|c|}{ Catalyst } & \multirow{3}{*}{$\frac{\text { Yield }}{\%}$} & \multicolumn{3}{|c|}{ THF-sol. part ${ }^{\mathrm{c}}$} & \multicolumn{2}{|c|}{ THF-insol. part } \\
\hline & & & Temp $^{\mathbf{b}}$ & & Yield & & & Yield & \\
\hline & & & ${ }^{\circ} \mathrm{C}$ & & $\%$ & & & $\%$ & \\
\hline 1 & $(S)-1$ & $n$-BuLi & r.t. & 99 & 96 & +354 & 39 & 0 & \\
\hline 2 & $(R)-1$ & $n$-BuLi & -40 & 48 & 1 & & & $47(-)^{f}$ & 209 \\
\hline 3 & $(R)-1$ & $n$-BuLi & -78 & 53 & 1 & & & $52(-)^{f}$ & 171 \\
\hline 4 & $(S)-1$ & $t$-BuLi & r.t. & 97 & 87 & +384 & 65 & 9 & \\
\hline 5 & $(S)-1$ & $t$-BuLi & -40 & 95 & 93 & +355 & 48 & 0 & \\
\hline 6 & $(S)-1$ & $t-\mathrm{BuLi}$ & $-78^{\mathrm{g}}$ & 95 & 93 & +362 & 35 & 0 & \\
\hline 7 & $(S)-1$ & $t-\mathrm{BuLi}$ & $-78^{\mathrm{h}}$ & 95 & 94 & +345 & 46 & 0 & \\
\hline 8 & $(S)-1$ & $t-\mathrm{BuLi}$ & $-78^{i}$ & 97 & 95 & +346 & 46 & 0 & \\
\hline
\end{tabular}

a The polymerization was carried out in an $H$-branched ampoule at $[\operatorname{TrMA}] /[\mathrm{Li}]=20$.

b Temperature at which the catalyst was prepared for $30 \mathrm{~min}$.

c Oligomers soluble in benzene- $50 \%$ hexane were removed.

d $C=0.5 \mathrm{~g} \mathrm{dl}^{-1}$ in THF.

e Determined from GPC charts of the poly(MMA)s derived from the polymers.

${ }^{f}$ Expected rotation sign of the polymer from the optical resolution of (RS)-hexahelicene (ref 9 ).

s Used immediately after preparation.

${ }^{\mathrm{h}}$ Used after being left to stand for $1 \mathrm{~h}$ at $-78^{\circ} \mathrm{C}$.

i Used after being left to stand for $24 \mathrm{~h}$ at $-78^{\circ} \mathrm{C}$.

product. These results clearly indicate that the lithiation of toluene can be prevented by lowering the complexation temperature. Therefore, the asymmetric polymerizations of TrMA and D2PyMA in toluene at $-78^{\circ} \mathrm{C}$ were further investigated using chiral complexes prepared from $n$ - or $t$-BuLi and 1 at various temperatures. The results are summarized in Tables I and II. All obtained polymers were found to be highly isotactic.

$n$-BuLi complexed with 1 in toluene at -40 or $-78^{\circ} \mathrm{C}$ was not a suitable initiator for either monomer, since a high-molecular-weight polymer was the main product in every run. As for the above poly(TrMA)s, it was impossible to measure their optical rotations, because they were insoluble in common organic solvents. However, the poly(TrMA)s exhibited a high ability of chiral recognition in the optical resolution of racemic hexahelicene, ${ }^{9}$ as shown in Table I. These results indicate that the THFinsoluble polymers have helical conformations probably prevailing in a left-handed screw sense. ${ }^{12}$ On the other hand, it was difficult to resolve hexahelicene on the THF-insoluble poly(D2PyMA), as expected from its low optical rotation (Run no. 11 in Table II).

One of the above polymerizations was terminated with a small amount of methanol at an initial stage of $5 \mathrm{~min}$ after the initiation, and the solvents and volatile materials were trapped under high vacuum. The GC-mass analysis of the mixture showed that butyl isopropenyl ketone (BIPK) was contained as one of the components. ${ }^{13}$ Hatada et al. have demonstrated that such a vinyl ketone is produced by a side-reaction in the anionic polymerization of methyl methacrylate (MMA) with $n$-BuLi. ${ }^{14}$ In the polymerizations of TrMA and D2PyMA, it is likely that some of the $n$-BuLi complexes attack the carbonyl groups of the present monomers as well. The partial consumption of the initiator results in considerable increase in the molecular weight of the resulting polymer. 


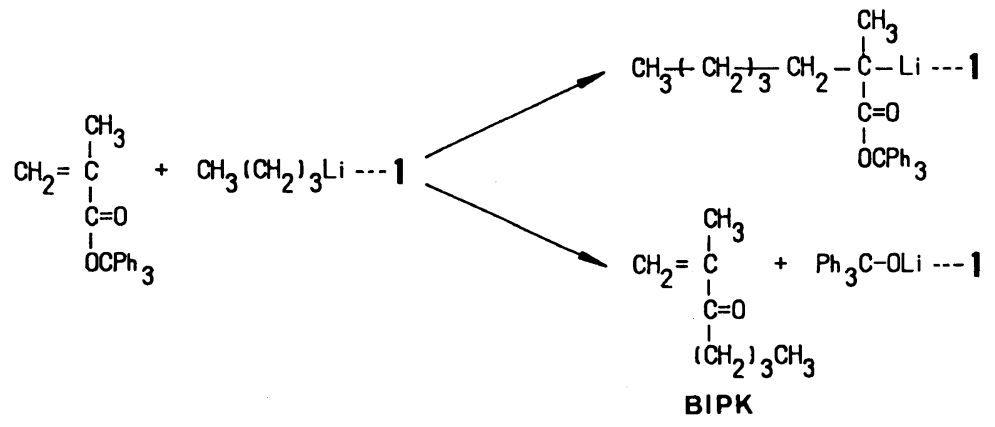

On replacement of $n$-BuLi with $t$ - BuLi, there are drastic changes in the polymerization results, as shown in Table I. All the catalysts prepared from $t$-BuLi and 1 in a wide range from room temperature to $-78^{\circ} \mathrm{C}$ produced
THF-soluble poly(TrMA)s in high yields. The specific rotations of the polymers were comparable to that reported for optically pure poly(TrMA). ${ }^{3}$

Figure 1 represents the ${ }^{1} \mathrm{H}$ NMR spectra of

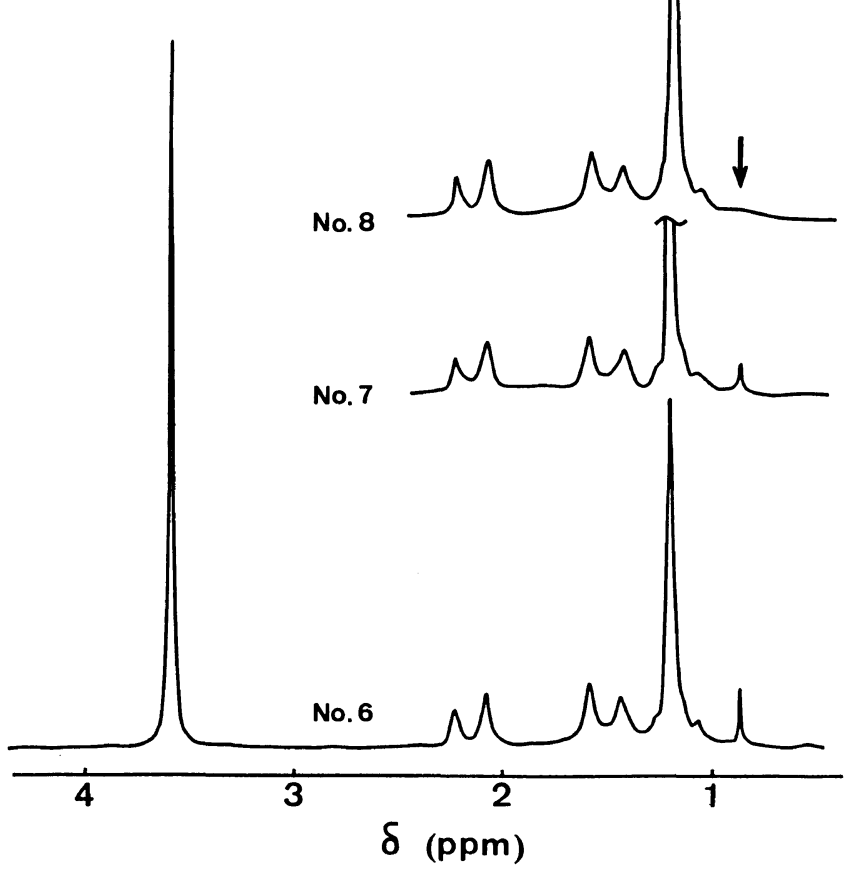

Figure 1. ${ }^{1} \mathrm{H}$ NMR spectra of poly(MMA)s derived from poly(TrMA)s obtained by chiral catalysts prepared from $t$-BuLi and 1. (See Runs no. 6, 7, and 8 in Table I.)

the poly(MMA)s derived from the above poly(TrMA)s. Each spectrum showed a typical pattern of isotactic poly(MMA) with a rather low molecular weight. $^{8}$ However, an additional peak of weak intensity was observed around $0.9 \mathrm{ppm}$ in the spectra of the
poly(MMA)s from Runs no. 6 and 7 in Table I. The peak was apparently attributed to a terminal $t$-butyl group. Polymer 6 was obtained using the $t$-BuLi/1 complex immediately after preparation at $-78^{\circ} \mathrm{C}$. The relative peak intensity due to the $t$-butyl group 
in polymer 6 was nearly close to that expected from its degree of polymerization $(\overline{\mathrm{DP}}=35)$ $\left(\overline{\mathrm{DP}}_{\text {calcd. by NMR }}=34\right)$, provided each polymer molecule had one $t$-butyl group. In addition, the assumed polymer structure may be also explained by the ${ }^{13} \mathrm{C}$ NMR spectrum. Besides strong signals due to isotactic poly(MMA), four signals among several unusual ones, at $31.1(q), 31.9(s), 36.5(d)$, and 42.9 (unclear) ppm, were tentatively assigned to the primary and quaternary carbons of $t$-butyl group at the $\alpha$-end, and the methine and methylene carbons of the $\omega$-MMA unit, respectively, according to Hatada's assignment ${ }^{15}$ :

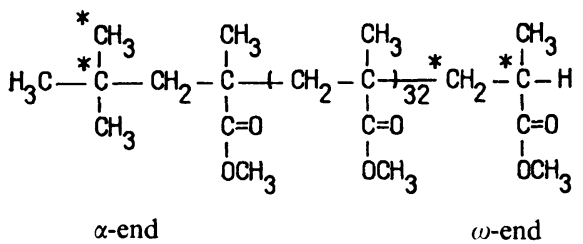

Taking the large optical rotation of the polymer into consideration, it is conceivable that 1 complexes with $t$-BuLi at as low temperature as $-78^{\circ} \mathrm{C}$ and the resulting complex functions as the chiral initiator. $t$-BuLi alone produced mainly THF-insoluble poly(TrMA) in only a $43 \%$ conversion.

When the $t-\mathrm{BuLi} / \mathbf{1}$ complex was left to stand for 1 to $24 \mathrm{~h}$ at $-78^{\circ} \mathrm{C}$ before use, the obtained polymers 7 and 8 were distinct in molecular weight from the above polymer 6 . Interestingly, the peak of the $t$-butyl group weakened in polymer 7 , and did not appear at all in polymer 8 . Although the two polymers had higher molecular weights compared with that of polymer 6 , the content of the $t$-butyl group greatly decreased well beyond the increase of molecular weight. This suggests that the intermediate $t$-BuLi/1 complex is not so stable even at $-78^{\circ} \mathrm{C}$ that it changes gradually into the corresponding BzLi complex. A further NMR study of polymers 4 and 5 suggests that the catalyst solutions prepared at higher temperatures than $-78^{\circ} \mathrm{C}$ consist solely of the BzLi complex at least after standing it for $30 \mathrm{~min}$.

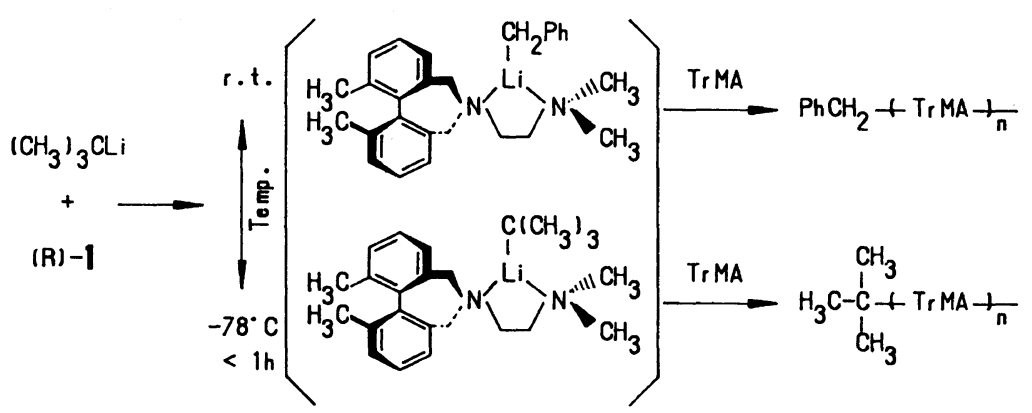

The catalysts used for Runs no. 1 and 4 in Table I were prepared under the same conditions from $n$ - and $t$-BuLi, respectively. The obtained polymers differed considerably in molecular weight, although the initiators were probably the same $\mathrm{BzLi} / \mathbf{1}$ complexes. The difference seemed to arise from efficiency in the conversion of each alkyllithium into BzLi. To confirm this point, concentrations of the generated BzLi were determined. Each catalyst solution starting from two alkyllithiums was treated with dry carbon dioxide, ${ }^{16}$ and the resulting phenylacetic acid was isolated. Consequently, it was found that the conversion of $n$-BuLi into $\mathrm{BzLi}$ proceeded to a $72 \%$ yield and that of $t$-BuLi only a $44 \%$ yield:

$$
\mathrm{CH}_{3}\left(\mathrm{CH}_{2}\right)_{3} \mathrm{Li}+1 \frac{\mathrm{PhCH}_{3}}{\mathrm{Y} .72 x}-\mathrm{PhCH}_{2} \mathrm{Li}--1-\frac{\mathrm{PhCH}_{3}}{\mathrm{Y} .44 x}\left(\mathrm{CH}_{3}\right)_{3} \mathrm{CLi}+1
$$


In the former carbonylation, used 1 was recovered nearly quantitatively, and the amounts of total lithium compounds possible to react with the hydroxylic group of 2,5-dimethoxybenzyl alcohol ${ }^{17}$ were almost equal before and after the addition of 1 . These results indicate that a part of $n$-BuLi activated by complexation presumably decomposes at room temperature. The decomposition products are guessed to be butene and lithium hydride which cannot initiate the polymerization. On the contrary, workup of the latter carbonylation mixture followed by distillation gave only $79 \%$ of 1 , and the other remained as unvolatile materials. Their precise structures have not been elucidated yet. The ${ }^{1} \mathrm{H}$ NMR spectrum, however, suggested that they were derived from 1. From these findings, it is considered that the $t$ - $\mathrm{BuLi} / \mathbf{1}$ complex lithiates not only toluene but also the ligand, together with the decomposition of the activated $t$ - BuLi itself at room temperature. The latter two reaction processes will diminish at lower temperature and the conversion into $\mathrm{BzLi}$ will be more preferable. This may be another reason for the decrease of the molecular weight of the polymer obtained at lowering the complexation temperature of $t$-BuLi and $\mathbf{1}$.

\section{Polymerization of D2PyMA}

D2PyMA was also successfully polymerized in toluene at $-78^{\circ} \mathrm{C}$ with the above described chiral catalysts, except for the $n$-BuLi complex. It can be seen from Table II that all the catalysts of $(S)$-configuration produced more or less preferentially $(+)$-polymers, similar to the polymerization of TrMA. The BzLi/ 1 complex generated from $n$-BuLi at room temperature gave almost quantitatively an optically active polymer (Run no. 9 in Table II) composed of the THF-soluble and insoluble parts, whose optical rotations differed significantly from each other. Thus, the solvent-fractionation was required to obtain poly(D2PyMA) of higher optical rotation. In contrast to THF-insoluble poly(TrMA), most of the THF-insoluble poly(D2PyMA) was soluble in $\mathrm{CHCl}_{3}$. All were soluble in $\mathrm{CHCl}_{3}-10 \% \mathrm{CF}_{3} \mathrm{CH}_{2} \mathrm{OH}$, although the polymer mutarotated in an accelerated rate in the mixed solvent rather than in

Table II. Asymmetric polymerization of D2PyMA using chiral complexes of alkyllithiums with 1 in toluene for $48 \mathrm{~h}$ at $-78^{\circ} \mathrm{C}^{\mathrm{a}}$

\begin{tabular}{|c|c|c|c|c|c|c|c|c|c|c|c|}
\hline \multirow[b]{2}{*}{$\begin{array}{l}\text { Run } \\
\text { no. }\end{array}$} & \multicolumn{3}{|c|}{ Catalyst } & \multirow{2}{*}{$\frac{\text { Yield }}{\%}$} & \multirow[b]{2}{*}[\alpha]{$_{\mathrm{D}}^{25 \mathrm{c}}$} & \multicolumn{3}{|c|}{ THF-sol. part } & \multicolumn{3}{|c|}{ THF-insol. part } \\
\hline & $\begin{array}{c}\text { Chiral } \\
\text { diamine }\end{array}$ & $\begin{array}{l}\text { Alkyl- } \\
\text { lithium }\end{array}$ & $\frac{\text { Temp }^{\mathrm{b}}}{{ }^{\circ} \mathrm{C}}$ & & & $\frac{\text { Yield }}{\%}$ & {$[\alpha]_{\mathrm{D}}^{25 c}$} & $\overline{\mathrm{DP}}^{\mathrm{d}}$ & $\frac{\text { Yield }}{\%}$ & {$[\alpha]_{\mathrm{D}}^{25 \mathrm{c}}$} & $\overline{\mathrm{DP}^{\mathrm{d}}}$ \\
\hline $9^{e}$ & $(R)-1$ & $n$-BuLi & r.t. & 97 & -294 & 12 & -156 & 47 & 85 & $-312^{f}$ & 66 \\
\hline $10^{\mathrm{e}}$ & $(R)-1$ & $n-\mathrm{BuLi}$ & r.t. & $36^{\mathrm{g}}$ & -285 & 32 & -281 & 35 & 4 & & \\
\hline 11 & $(S)-1$ & $n-\mathrm{BuLi}$ & -78 & 28 & +40 & 1 & & & 27 & +39 & 80 \\
\hline 12 & $(S)-1$ & $t$-BuLi & r.t. & 96 & +258 & 40 & +245 & 38 & 56 & +249 & 58 \\
\hline 13 & $(S)-1$ & $t$-BuLi & $-78^{\mathrm{h}}$ & 99 & +340 & 99 & $+340^{i}$ & 36 & 0 & & \\
\hline
\end{tabular}

a The polymerization was carried out in an $H$-branched ampoule at [D2PyMA]/[Li] $=20$.

b Temperature at which the catalyst was prepared for $30 \mathrm{~min}$.

c $C=1.0 \mathrm{~g} \mathrm{dl}^{-1}$ in $\mathrm{CHCl}_{3}-10 \% \mathrm{CF}_{3} \mathrm{CH}_{2} \mathrm{OH}$.

d Determined from GPC charts of the poly(MMA)s derived from the polymers.

e The catalyst solution was added to the monomer solution by a syringe.

${ }^{f}[\alpha]_{365}^{25}-1186^{\circ}$. The polymer was partly insoluble in $\mathrm{CHCl}_{3}$.

8 For $6 \mathrm{~h}$.

h Used immediately after preparation.

${ }^{i}[\alpha]_{365}^{25}+1382^{\circ}$. The polymer was soluble in $\mathrm{CHCl}_{3}$. 
THF or $\mathrm{CHCl}_{3} .{ }^{5}$ Optical measurements for poly(D2PyMA)s were carried out just after the polymers had been dissolved in $\mathrm{CHCl}_{3}-$ $10 \% \mathrm{CF}_{3} \mathrm{CH}_{2} \mathrm{OH}$ (within less than $15 \mathrm{~min}$ ).

It has been already found that the specific rotation of poly(TrMA) helix tends to become larger as molecular weight increases. ${ }^{9}$ Poly(D2PyMA) 9 was isolated after completion of the polymerization. The molecular weight of the THF-soluble part in polymer 9 was lower than that of the insoluble one, but the two were not different in high isotacticity. On the other hand, poly(D2PyMA) 10 was obtained by polymerization for $6 \mathrm{~h}$. The polymer had a low $\overline{\mathrm{DP}}$, so that most of it was soluble in THF. The THF-soluble part, however, showed a higher optical rotation of $[\alpha]_{D}^{25}$ $-281^{\circ}$ than that of the THF-soluble part of polymer 9 . Therefore, the low optical rotation of the latter polymer may not be attributable only to simple effects of molecular weight, which will be explained later.

A higher optical rotation was recorded for poly(D2PyMA) produced by the fresh $t$ - BuLi/ 1 complex prepared at $-78^{\circ} \mathrm{C}$ (Run no. 13 in Table II). All the polymer was soluble in THF as well as in $\mathrm{CHCl}_{3}$. The specific rotation of $[\alpha]_{D}^{25}+340^{\circ}\left(+1382^{\circ}\right.$ at $\left.365 \mathrm{~nm}\right)$ was nearly comparable with the highest value of $[\alpha]_{365}^{25}$ $-1403^{\circ 5}$ reported so far for optically active poly(D2PyMA), which was separated from the raw polymer of lower optical rotation by $\mathrm{THF}$ fractionation.

The above two poly(D2PyMA)s 9 and 13 were analyzed by GPC. These polymers were converted into poly(MMA)s, ${ }^{9}$ because polymer 9 was partly insoluble in THF. In comparison with both broken curves in Figure 2, it

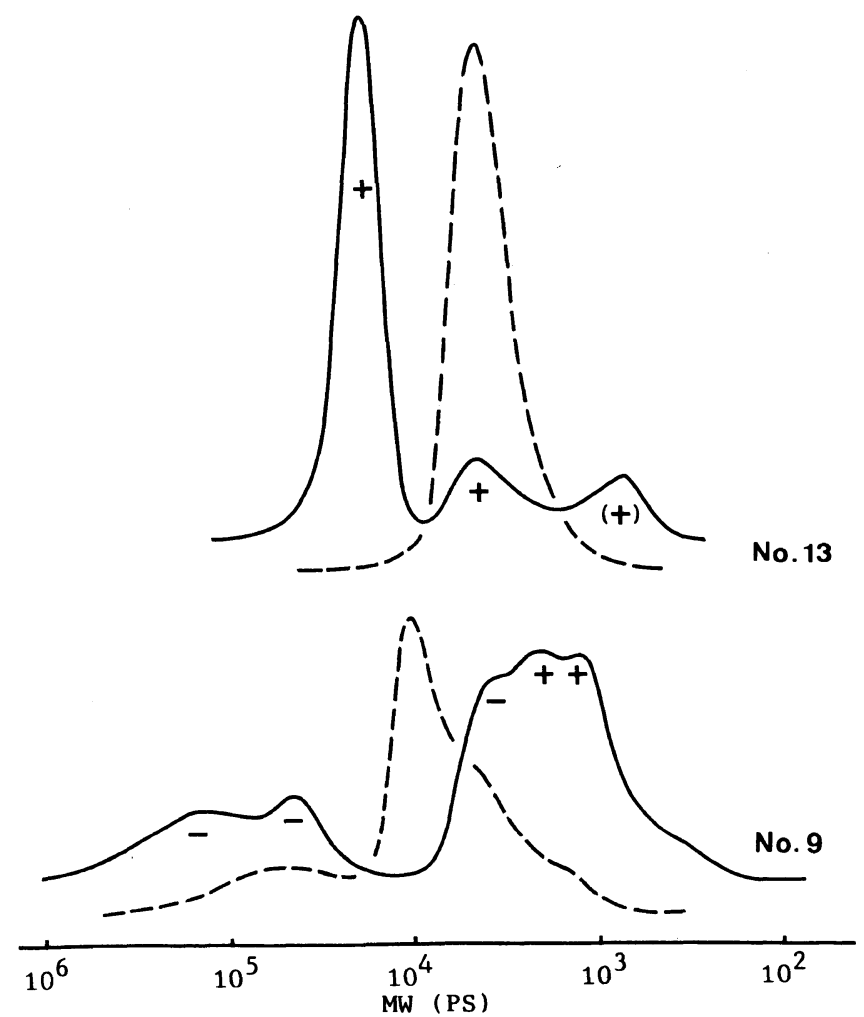

Figure 2. GPC curves of THF-soluble poly(D2PyMA)s (- - and poly(MMA)s (----) derived from poly(D2PyMA)s. (See Runs no. 9 and 13 in Table II). 
was obvious that polymer 9 showed a more complicated-molecular-weight distribution than that of polymer 13. It has been often observed that molecular-weight distributions of poly(TrMA)s and poly(D2PyMA)s become progressively complicated as the asymmetric polymerizations proceed in toluene.,9 This was the case with poly(D2PyMA) 9 obtained by the BzLi complex at the later stage of the polymerization. On the contrary, poly(MMA) 13 exhibited a very simple curve, indicating that the polymer had a lower molecular weight $(\overline{\mathrm{DP}}=36)$ with a narrow distribution.

In addition, the THF-soluble parts of the above poly(D2PyMA)s were directly chromatographed without transesterification. The GPC results monitored on both RI and polarimetric detectors are shown as solid curves in Figure 2, where signs of $+/-$ refer to the rotation signs of respective peaks. Most of polymer 13 was eluted in a main peak, although the pattern slightly differed from the unimodal curve of the corresponding poly(MMA) mentioned above. Every peak showed a positive rotation, except for the lowest-molecular-weight one. Its rotation sign was ambiguous probably because the oligomers could not take on an ordered conformation. ${ }^{6}$

The THF-soluble part of polymer 9 showed a complicated pattern composed of several peaks. Some showed negative rotations, but the others positive rotations, contrary to the case of polymer 13. Two peaks at a highermolecular-weight region were expected to correspond to the THF-insoluble part, but not all, from the rotation signs and elution volumes of these peaks. A similar GPC analysis of polymer 10, however, exhibited the existence of only (-)-polymers. Therefore, there is the possibility that the low-molecular-weight $(+)$ polymers in polymer 9 are formed, probably at the later stage of the polymerization, by another active species different from the main species forming ( - )-polymers. Okamoto et al. have pointed out that not only helical
Table III. Specific rotations of THF-soluble poly-

(D2PyMA)s obtained by the polymerization with the $t$-BuLi/(S)-1 complex in toluene at $-78^{\circ} \mathrm{C}$

\begin{tabular}{rlrrrrrr}
$\begin{array}{c}\text { Polymer } \\
\text { yield } / \%\end{array}$ & 11 & 20 & 35 & 48 & 60 & 87 & 99 \\
{$[\alpha]_{D}^{25}$ a $/ \%$} & +141 & +164 & +210 & +257 & +296 & +328 & +340 \\
\hline
\end{tabular}

a $C=1.0 \mathrm{~g} \mathrm{dl}^{-1}$ in $\mathrm{CHCl}_{3}-10 \% \mathrm{CF}_{3} \mathrm{CH}_{2} \mathrm{OH}$.

enantiomers but also structural isomers associated with arrangement of the pyridyl group possibly exist as optical isomers of poly(D2PyMA). ${ }^{5}$ Accordingly, it is unclear whether the $(+)$ - and $(-)$-polymers contained in polymer 9 are enantiomeric or not.

Table III shows the specific rotations of THF-soluble poly(D2PyMA)s obtained in different yields by the polymerization with the $t$ $\mathrm{BuLi} /(S)-1$ complex. It was obvious that the specific rotation increased with the polymer yield. Samples showing $[\alpha]_{D}^{25}+164^{\circ}$ and $+210^{\circ}$ eluted near the molecular-weight region of GPC observed for (+)-polymers in polymer 9 . Even if these polymers are not the same stereoisomers, it is considered that the $(+)$-polymers in polymer 9 have less high specific rotations owing to the low $\overline{\mathrm{DP}}$. On fractionation of polymer 9 in THF, the $(+)$ polymers of lower molecular weight may be collected largely to the soluble part. Compensation for rotations among the $(+)$ and (-)-polymers results in the low specific rotation of this part.

In conclusion, it was found that the fresh $t$ $\mathrm{BuLi} / \mathbf{1}$ complex prepared at $-78^{\circ} \mathrm{C}$ was an excellent initiator for the asymmetric polymerizations of both TrMA and D2PyMA in toluene. This catalyst initiated each of the polymerizations with high efficiency, probably because of the absence of any lithiation accompanying the complex formation and bulkiness of the anion to avoid carbonyl attack on the ester monomers. During the polymerization, either a right- or left-handed helix grew exclusively under the control of the chirality of $\mathbf{1}$, while generation of other helical stereoisomers 
or their following growth ${ }^{6}$ was suppressed almost entirely. Thus, the obtained polymers had almost pure one-handed helicity and limited molecular weights.

Acknowledgments. The authors thank Dr. Yoshio Okamoto of Osaka University for stimulating discussions. Financial support from the Ministry of Education, Science and Culture of Japan (Grant-in-Aid for Encouragement of Young Scientists, No. 61750855) is gratefully acknowledged by one of us (S. K.).

\section{REFERENCES AND NOTES}

1. Y. Okamoto, K. Suzuki, K. Ohta, K. Hatada, and H. Yuki, J. Am. Chem. Soc., 101, 4763 (1979).

2. Y. Okamoto, K. Suzuki, and H. Yuki, J. Polym. Sci., Polym. Chem. Ed., 18, 3043 (1980).

3. Y. Okamoto, I. Okamoto, and H. Yuki, J. Polym. Sci., Polym. Lett. Ed., 21, 601 (1983).

4. Y. Okamoto, M. Ishikura, K. Hatada, and H. Yuki, Polym. J., 15, 851 (1983).

5. Y. Okamoto, H. Mohri, M. Ishikura, K. Hatada, and H. Yuki, J. Polym. Sci., Polym. Symp., 74, 125 (1986).

6. Y. Okamoto, E. Yashima, T. Nakano, and K.
Hatada, Chem. Lett., 759 (1987).

7. Y. Okamoto, S. Honda, I. Okamoto, H. Yuki, S. Murata, R. Noyori, and H. Takaya, J. Am. Chem. Soc., 103, 6971 (1981).

8. S. Kanoh, H. Suda, N. Kawaguchi, and M. Motoi, Makromol. Chem., 187, 53 (1986).

9. S. Kanoh, N. Kawaguchi, T. Sumino, Y. Hongoh, and H. Suda, J. Polym. Sci., Part A, Polym. Chem., 25, 1603 (1987).

10. S. Kanoh, H. Muramoto, N. Kobayashi, M. Motoi, and H. Suda, Bull. Chem. Soc. Jpn., 60, 3659 (1987)

11. S. Kanoh, H. Muramoto, K. Maeda, N. Kawaguchi, M. Motoi, and H. Suda, Bull. Chem. Soc. Jpn., in press.

12. Y. Okamoto, I. Okamoto, and H. Yuki, Chem. Lett., 853 (1981).

13. The ketone was confirmed by the mass spectral cracking pattern, which was almost consistent with that of the authentic sample prepared according to the method in ref 14 .

14. K. Hatada, T. Kitayama, S. Okahata, and H. Yuki, Polym. J., 13, 1045 (1981).

15. The chemical shifts observed in $\mathrm{CDCl}_{3}$ differed within $2 \mathrm{ppm}$ from those observed in nitrobenzene- $d_{5}$ by K. Hatada, K. Ute, K. Tanaka, M. Imanari, and N. Fujii, Polym. J., 19, 425 (1987).

16. The acid and its methyl ester were confirmed by their selected spectral data; W. Langer, Jr., U. S. Patent, 3,769,345 (1973).

17. M. R. Winkle, J. M. Lansinger, and R. C. Ronald, $J$. Chem. Soc., Chem. Commun., 87 (1980). 